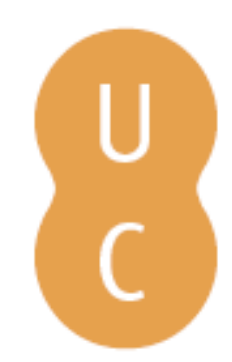

\title{
nommalina
}

\section{Natural Subjectivity: An Ethical Issue in the Naturalization of the Phenomenological Concept of Subject}

\author{
Autor(es): Delescu, Lucian \\ Publicado por: Imprensa da Universidade de Coimbra \\ URL \\ persistente: URI:http://hdl.handle.net/10316.2/43579 \\ DOI: $\quad$ DOl:https://doi.org/10.14195/978-989-26-1380-2_6 \\ Accessed : $\quad$ 26-Apr-2023 11:21:35
}

A navegação consulta e descarregamento dos títulos inseridos nas Bibliotecas Digitais UC Digitalis, UC Pombalina e UC Impactum, pressupõem a aceitação plena e sem reservas dos Termos e Condições de Uso destas Bibliotecas Digitais, disponíveis em https://digitalis.uc.pt/pt-pt/termos.

Conforme exposto nos referidos Termos e Condições de Uso, o descarregamento de títulos de acesso restrito requer uma licença válida de autorização devendo o utilizador aceder ao(s) documento(s) a partir de um endereço de IP da instituição detentora da supramencionada licença.

Ao utilizador é apenas permitido o descarregamento para uso pessoal, pelo que o emprego do(s) título(s) descarregado(s) para outro fim, designadamente comercial, carece de autorização do respetivo autor ou editor da obra.

Na medida em que todas as obras da UC Digitalis se encontram protegidas pelo Código do Direito de Autor e Direitos Conexos e demais legislação aplicável, toda a cópia, parcial ou total, deste documento, nos casos em que é legalmente admitida, deverá conter ou fazer-se acompanhar por este aviso.

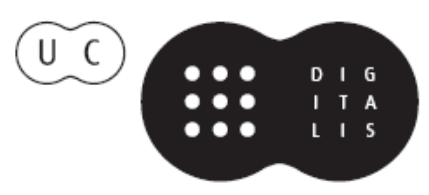




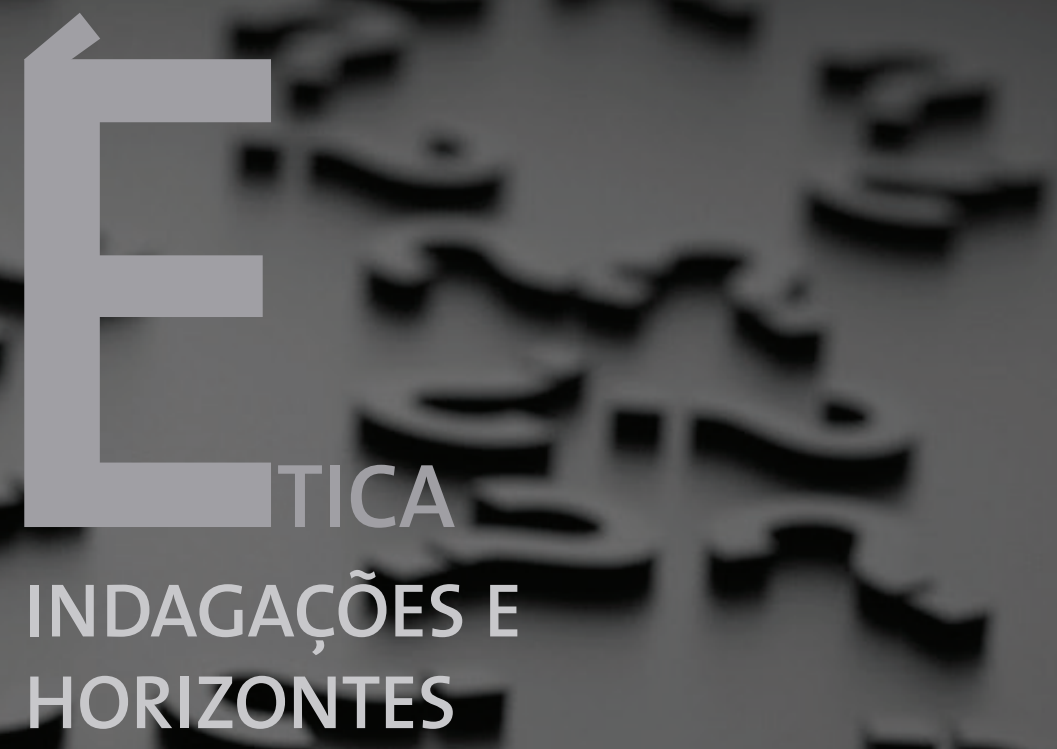

Maria Formosinho Paulo Jesus Carlos Reis (Coord.)
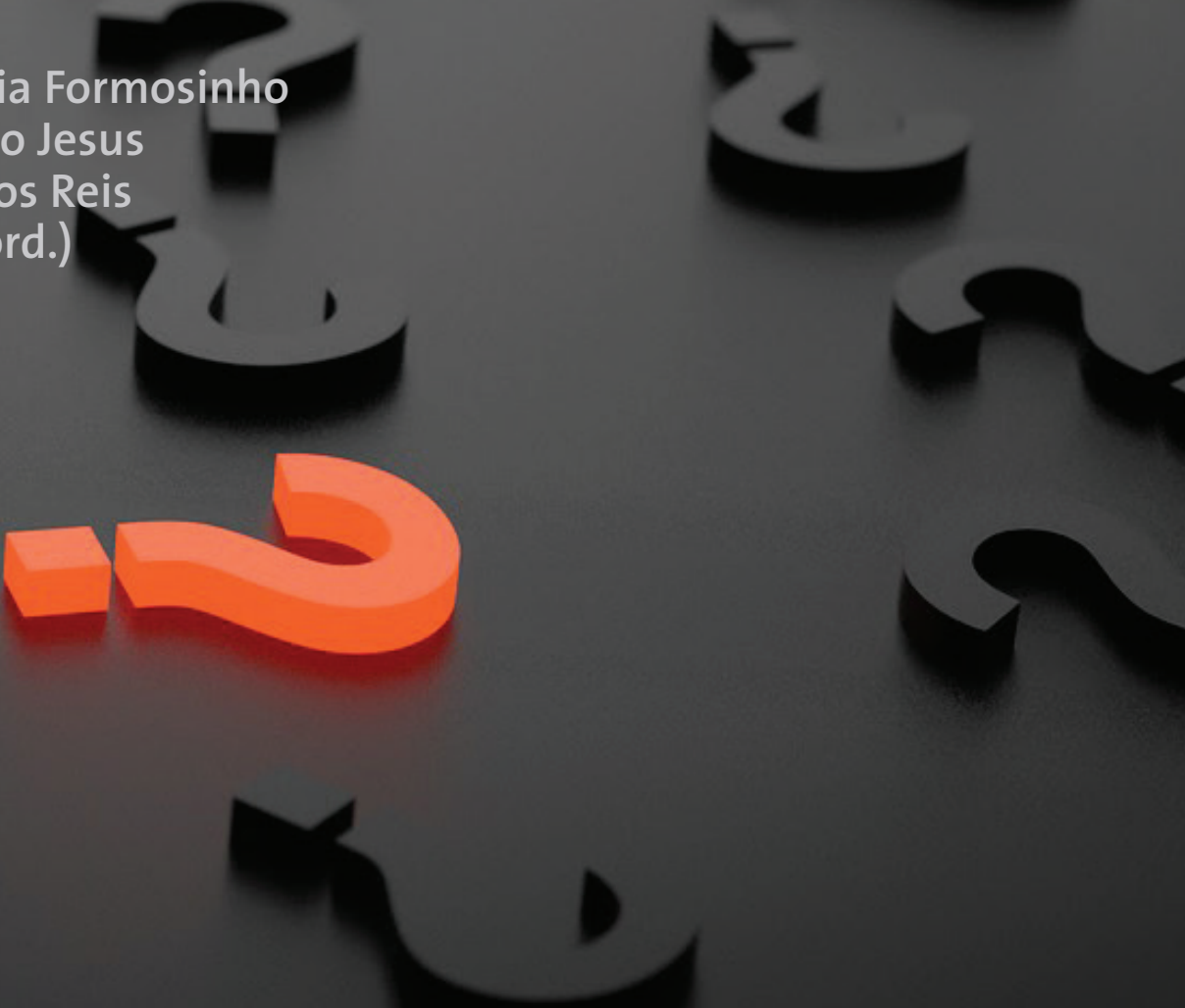


\title{
CAPÍTULO VI
}

\section{NATURAL SUBJECTIVITY: \\ AN ETHICAL ISSUE IN THE NATURALIZATION OF THE PHENOMENOLOGICAL CONCEPT OF SUBJECT}

\author{
Lucian Delescu ${ }^{1}$
}

\section{Introduction}

Classical phenomenology is locked inside a form of transcendentalism and so it is the entire tradition which made it possible. This is the reason (some think) why it must become object of a systematic criticism meant to convince us that phenomenology abandoned the world of facts and construed a nonrealistic account of consciousness. This argument must be understood as part of a much broader form of criticism philosophical naturalism erected not only against phenomenology but against all prephenomenological theories which employ themselves to defend nonnaturalistic accounts of consciousness. It was first Hume and the logical positivists to address these theories in a critical manner in order for later contemporary naturalists to reinvigorate the same kind of argument. But similar replies have been also put forward by those usually considered defenders of classical phenomenology (the so-called "postphenomenologists"). There is however a third category of philosophers, the so-called "transcendentalists", who defended Husserl and continue to do so. I think some of the transcendentalists were onto something but they ultimately failed to do justice to classical phenomenology for the same two particular reasons I believe the postphenomenologists have failed to convince.

Ontologically speaking they assume that classical phenomenology continues the path of dualism because it turned against philosophical naturalism (empiricism and logical positivism) and advocated a "transcendental" account of consciousness where that means a consciousness beyond the competence of

\footnotetext{
${ }^{1}$ Berkeley College, New York, USA.
} 
natural sciences. As a result, much of the contemporary philosophical debate is consumed by the impossibility to settle the differences between a transcendental phenomenology where consciousness remains beyond realistic analyses and a postphenomenology where consciousness is nothing but contextual experience. However, Husserl has equally rejected dualism and idealism, and attempted to balance the epistemological tension between naturalistic and nonnaturalistic prephenomenological theories of consciousness:

Psychic faculties — or, as they later come to be called, psychic dispositions - become analogues of physical forces, titles for merely causal proprieties of the soul, either belonging to its own essence or arising from its causal relationship with the living body, but in any case to such a way that reality and causality are understood in the same way on both sides. Of course, right away, in Berkeley and Hume, the enigmatic difficulties of such an interpretation of the soul announce themselves and press toward immanent idealism which swallows up one of the two parallels. Yet up through the nineteenth century this changes nothing about the way in which psychology and physiology, which supposedly follow experience, in fact do their work. It was easy to carry the "idealistic" naturalism of the immanent philosophy of those successors of Locke over into the dualistic psychology. The epistemological difficulties made so noticeable by Hume were overcome - precisely through epistemology. Thus the growing acquisition of obviously valuable empirical facts took on the appearance of having a meaning which could be understood philosophically. (Husserl, 1970, p. 231)

Methodologically speaking these philosophers seem to have never considered phenomenology as one of the most significant attempts to actually naturalize consciousness where that means doing phenomenological psychology. That is a logical consequence of their understanding of phenomenological consciousness.

\section{Concern and skepticism regarding a phenomenological psychology}

Now, there are various strategies to move ahead the failure of these interpretations. The most direct is to reconnect phenomenology with appropriate applied research fields. That is for now a rather distant scenario considering the incredible resistance many philosophers still display regarding this particular strategy but also because not all agree regarding the future of phenomenology. I guess we have to spend more time clarifying why the above interpretations failed, although the fundamental problem is not ultimately the meaning of the phenomenological theory of consciousness, but rather to understand to what extent the phenomenological description of consciousness is accurate where that means to actually trying to understand consciousness per se. Anyway, when one speaks about naturalizing 
phenomenological consciousness there seems to be widespread moral concern. The way this concern, otherwise legitimate, has been formulated contributes directly to the dramatic situation in which phenomenology is today. In an ideal scenario it should have triggered a rigorous inquiry into the nature of consciousness. It made instead possible radical positions, such as the attempt to deconstruct or to maintain it far from a realistic dialogue with psychology. From my point of view, naturalizing phenomenology means paving the way to pass from philosophical to phenomenological psychology, hence reestablishing the dialogue with psychology and eventually, as strange as it may sound, reestablishing the dialogue with phenomenology itself. For others, especially for transcendentalists, but also for continentals even if they rarely admit it, that is a compromise with philosophical naturalism. It is rather unclear how many of these philosophers are willing to acknowledge that there is an objective distinction between experimental psychology and natural sciences in general, and phenomenological/ philosophical naturalism which are theories of consciousness; and so the debate has to be settled between phenomenology and naturalism as two competing philosophical theories. Judging by their reaction they seem to remain unshakably skeptical regarding any attempt to "unbracket the subject", even for the sake of the argument so while they put forward various interpretations the problem remains unsolved. It is nevertheless true that like empiricists in the past, contemporary naturalists have almost entirely shielded psychology from any other theory, which explains why for some naturalizing phenomenology is a window into a traumatizing past. For others this might be an opportunity to explore aspects of human consciousness never observed before. As Michael Dummett recently argued, philosophy has made possible sciences but it got to remain outside experimental research (Dummett, 2010, p. 4). Some have engaged an experimental path but there is no experimental phenomenology in a large sense, probably because there isn't enough realistic talk about it. I do not argue for a naturalized phenomenology (yet). In spite of my previous optimism (Delescu, 2009), that requires to address the many nuances a constructive relation between phenomenology and psychology implies. But I'll try to talk about why an experimental phenomenology should exist. Before anything it requires to explore a number of fundamental aspects of phenomenological consciousness which cannot be discussed here. I shall walk for now with the "bracketing of the consciousness" for even if I have very different reasons I too think that the kind of naturalization the proponents of philosophical naturalism advocate, is not what we should aim for. I explore if there is room for something like a naturalized phenomenology, being aware that I will have to face naturalistic and transcendentalist skepticism at the same time. That is a widespread concern at least among transcendentalists which are to a great extent responsible for the dramatic isolation of phenomenology with respect to psychology and natural sciences in general. Except Merleau-Ponty, who made a radical attempt to naturalize phenomenology qualifying him in principle as a naturalist, most phenomenologists have maintained a skeptical attitude toward any form of naturalism. To sum up, there are not only epistemological and 
ontological fundamental difficulties but also ethical aspects one has to overcome if willing to elaborate a phenomenological psychology.

Now, one cannot simply challenge such moral skepticism without justification and without providing an alternative. To that extent I think classical phenomenology has recognized the intrinsicness of conscious experiences, more precisely, that they occur no matter what and they are worldly lived (Husserl, 1970, pp. 82-83). Let me reformulate this: conscious experience is a fundamental feature of the natural world where "natural" does not mean "naturalistic". After all, if something occurs I do not see how it could be recognized without being explored. So much about justification. As for the alternative, think of what Husserl means by "phenomenological psychology": that is, roughly, the building up of a psychology capable of nonreductively exploring conscious experiences. From that point of view we shouldn't take the critique of empirical psychology to be a rejection of psychology as scientific domain but to be a critique of the naturalistic shielding. So much about the alternative. As I have already mentioned, to get to a phenomenological psychology one needs to overcome moral concerns and skepticism. The moral concern has been encrypted to the level of a form of transcendentalism (some dualism, some speculative views, and something else) which blocks the elaboration of a phenomenological experimental account of consciousness based on the idea that a naturalized phenomenology would imply a dramatic (negative) change of the way we understand consciousness. This is a matter which requires special attention. However, skepticism has a twofold implication. For most transcendental phenomenologists, it rather appears to be a good reason to avoid realistic explorations of conscious experiences. But one can ask, if indeed such moral concern exists, how can be avoided in the future or kept away from psychology and in general from realistic inquiries. Instead of preventing the compromise of consciousness, this assumption triggers a variety of theoretical reactions which have little in common with phenomenology. The "bracketing of the subject" is in good measure the consequence of the following question: how can conscious experiences be nonreductively described? The answer Husserl recurrently gives is clear: by putting forward a kind of psychology which can describe them - a phenomenological psychology.

The skepticism is to be found in philosophical naturalism. I have various observations with respect to naturalism but let us begin with two of them. With the involuntary assistance of transcendentalism, philosophical naturalism manufactured a view on phenomenology which, instead of clarifying the problem, delivered a radical interpretation of consciousness and perpetuated a blurred portrait of the phenomenological consciousness from the moment Husserl published his Cartesian Meditations to the present time ${ }^{2}$. In spite of his critique of dualism, some consider Husserl entangled with dualism (Churchland,

2 The same can be said about the numerous interpretations continental philosophers have formulated over the years. 
1988; Flanagan, 2001). The second is that the naturalistic model of ontology is reductive and compulsively rigid with respect to alternative ontological models, in particular those which are about to emerge from classical phenomenology. It is only very recently that affective and cognitive neurosciences reconsidered the ontological reality, if not of consciousness in all its complexity, at least of the emotional and cognitive processes. But while one can hope to enter a new era of the dialogue between phenomenology and psychology, I am not sure to what extent the dialogue between phenomenology and philosophical naturalism as well as the dialogue between the kind of phenomenologist I have in mind and current phenomenologists has the chance to succeed. Husserl argued that psychology should be primarily concerned with subjective events in the sense that for psychology something existing in a real world must be described according to its intrinsic complexity, keeping in mind that its theoretical (philosophical) intelligibility is nevertheless a subjective conception (a self-reflective reconstruction) not a pictorial description (Husserl, 2008). That doesn't entail that the natural world is an illusion but simply that one cannot substitute his feeling of objectiveness to the intrinsicness of natural occurrings as well as epistemological subjectivity doesn't entitle the substitution of a theory of consciousness with a theory of the natural (nonsubjective) occurrings. To that extent, any experiment is self-reflectively shaped and that makes possible the knowing of its object. Naturalists have always considered this a more or less relevant epistemological obstacle; yet again without being self-reflectively there is no knowledge whatsoever. Experimental psychology should account that between conceptualizing something and the intrinsic reality of what is to be explained there is only correlation. Thus, empirical analyses are limited, in that the experimental framework is in fact a modality to conceive something existing, not the objective depiction of something existing per se. This is not a reason to think phenomenology and psychology have nothing in common, rather to simply point out that psychology is experimental but also reflective. For Husserl explaining consciousness means to acknowledge the two indissolubly related methodological dimensions of consciousness: the experimental dimension which is the scope of psychology and the epistemological dimension which is the job of philosophy (Husserl, 1970, pp. 202-203). The distinction between them is meant to set out the margins of experimental psychology with respect to standard philosophical inquiries.

From a phenomenological point of view, one is entitled to "doubt" (in a phenomenological sense) the validity of the experimental psychology without doubting the role of psychology. To doubt is to have a constructive attitude toward science, hence ethical, if one aims to attain progress. For this specific point of view, phenomenology is that analytic tool which enables one to make sense of the results of an experiment for a broader understanding. Put it differently, when I have a perceptual experience, I am also "judging" the content of my perceptual experience in a sense that in order to make sense of what I see 
I have to self-reflectively process what I see. To go back for a moment to the transcendentalist interpretation of phenomenological consciousness (and so to the transcendentalist resistance regarding a phenomenological psychology), while they might be entitled on their own grounds to defend something like a dualistic account of consciousness, I am not sure to what extent phenomenological consciousness can be assimilated within their general view on consciousness just because Husserl criticized naturalism. One of the problems Husserl attempted to solve is how to explain one is able to grasp the objects from the natural reality without being reduced to objects, and, consequently, how it is possible to know something about the natural world without skepticism. Many are inclined to think that the core debate between phenomenology and naturalism turns around the nature of consciousness. That is true but incomplete. I think we tend to overlook the epistemological issues which arise when explaining consciousness. Once we decide to move toward a phenomenological psychology, we are able to find compatibility between phenomenology and psychology.

\section{Inside/outside the bracketing of consciousness: a case to consider}

To understand why some expressed moral concerns regarding the naturalization of phenomenology we must go back to the epistemological roots of the problem. I assume readers are familiar with these aspects so let me be brief. From Hume to logical positivists and their contemporary followers these philosophers assume that perception and sensation (feelings and emotions) are the only processes involved in acquiring knowledge. It follows that what exists, must be perceived; hence, it is logical to consider "natural" something perceptually sizeable. For Aristotle, Descartes, Kant, and Husserl, perception is one of the fundamental processes involved in acquiring knowledge but there is also something like making sense of what is perceived in a sense that in order to know that something exists one must indeed perceive or feel it but must also understand it. For instance, I see something happening in the street - a car accident - but if I plan to understand all possible causes of the accident in order to preempt future accidents (strategic planning), I have to think about before taking any decision. When an agent is involved in strategic planning s/he becomes intentional (self-reflectively) and therefore accountable (rewardable or punishable). The naturalistic reply is in principle the same: there is no perceptual evidence (they say "empirical") for self-reflectively; hence, there is nothing like an intentional agent. Besides the fundamental ontoepistemological problems and the mutual mischaracterizations one has also to deal with here, one must acknowledge the sharp division between a passive model of consciousness (the naturalistic model) and an intentional model of consciousness (the phenomenological model) where the second cannot be dismissed because of Descartes' association of self-reflexive processes with theism, especially once Husserl has detached 
himself from a number of metaphysical problems which belong to theology. To deny the intentional character of consciousness (which is what makes an experience properly speaking conscious) in the name of a personal disbelief is as simplistic as claiming that something exists only if I can see it especially in a scientific contemporary context which has surpassed the perceptual dogma of empiricism. But to come to our issue, the concern over the passive model of consciousness arises from its concrete implications. It is one thing to have, say, a world where most individuals are reduced to a passive (entirely dependent) audience and another where individuals are intentional agents. Considering both the political and economical implications one can understand why a number of philosophers find particularly troubling the attempt to reduce real consciousness to the naturalistic model. This is, very roughly, the reason for some to discourage a relation between classical phenomenology and naturalistic psychology, we must though distinguish between phenomenology having a relation with philosophical naturalism and having a relation with psychology.

In order to make even clearer this distinction I address here some problematic aspects within both naturalism and interpretations of phenomenology. They can be considered either complementary, if naturalism endorses at least something like the subjective nonreflectively character of experience, or fundamentally incompatible if naturalism evolves into externalism. To search for compatibility with naturalistic psychology is today more or less irrelevant since that kind of psychology is the experimental extension philosophical naturalism vigorously criticized from inside (Nagel, 1965; Putnam, 2002; Chalmers, 1996, 2010). It is nevertheless necessary to underline that strictly perceptual models of consciousness aren't sufficient for a future comprehensive psychology. The distinction between phenomenology and naturalism can be settled in terms of the failure versus the success to explain the very nature of the correlations humans make when solving basic arithmetical problems $(1+1=2)$. Naturalism claims to be able to explain such correlation without involving anything like nonnaturalistic accounts of consciousness. Although somehow distant from the topic I discuss here, I would like to briefly address the very interesting phantom limb experiment (Hirstein \& Ramachandran, 1997, 1998) in order to illustrate that passive models of consciousness and so passive psychology, which is the only kind of psychology one can get from philosophical naturalism, are not realistic. The phantom limb is also an excellent opportunity to think about a number of questions such as: can self-reflexivity be described in naturalistic terms where that means explaining something strictly according to perceptual principles? Note that by naturalism I have in mind that philosophical paradigm which begins by considering that something exists if perceived. Furthermore, can we dismiss the reality of intentional experiences because they have a biological function? Although it is not of my competence to unravel the biological dimension of this kind of experiences but rather to point out that they do occur and that they must be accounted for, let me say that it is puzzling why some think 
that discovering the biological function of intentionality should infirm the fact that intentional experiences do occur. I do not envisage here to rediscuss the metaphysical problem of consciousness which has been debated since Descartes but to make the case for the consistency of self-reflectively. In the phantom limb experiment we are presented a patient who lost his hand but continues to experience pain in the place of the lost hand years after the unfortunate accident occurred and after the wounds have been cured. The patient finally overcomes the pain by imagining first the missing hand and then by accepting that the lost hand is not there anymore so the brain "understands" the absence of the lost hand. There are two questions that came to my mind independently of the conclusions the scientific team which performed this experiment has arrived: (a) does the patient's realization of the fact that the hand is not anymore there involves minimal self-reflective processes, and if so (b) what kind of functions do self-reflectively experiences involve? I will not be dealing with the second question. That is a matter which, if we learned something from the contemporary debates, cannot be properly addressed at this stage, in any case cannot be addressed from a strictly philosophical point of view. It is however an excellent opportunity not only to discuss the relevance of self-reflexive experiences from both naturalistic and phenomenological perspectives, but also to reconsider the moral concern over the so-called naturalization of consciousness. Now, to cure the phantom limb one must intentionally convince the patient that the lost hand is lost. That implies to intentionally reset the brain. The possibility to change the view regarding an event is not even recognized by traditional naturalism for a variety of reasons. The naturalistic theory of ontology runs like that: there is a certain phenomenon that must be explained. So the explainer must "look" to the phenomenon, to begin to describe it according to the following strategy: isolate the phenomenon from others, describe its features and, reintegrate the phenomenon in a common class event (this is by the way the procedure that led Aristotle to the idea that conceptual discrimination is not strictly perceptual). Certainly, between discovering the cause of the phenomenon and describing it there is a difference, since not all the time the cause explains the phenomenon in itself. In the very moment when I analyze a certain phenomenon I use a strategy that allows me to introduce simple concepts. It is clear that philosophical naturalism does not recognize the intentional dimension of cognitive processes. Philosophical naturalism does not recognize cognitive processes at all, not even natural cognitive processes in a sense that for naturalists (at least for traditional naturalists) to admit something exists it must be perceived which is the reason why cognition is rather viewed as a subjectivist obstruction to the descriptive scientific process - a weakness.

Methodologically speaking, something like the phantom limb experience should be recognizable if searching only from a naturalistic point of view. Keep in mind that I discuss the issue from a strictly methodological point of view and I do not intend to make any big claims regarding the nature of conscious- 
ness. The phantom limb patient must undertake three stages in order to cure: a descriptive level which is meant to identify the problem, a reflective level when the patient thinks how to solve the problem, and a reconstructive level when the problem is actually solved. During all these levels a minimal self-awareness is always involved. If we attempt to explain these stages from both a naturalistic and a phenomenological point of view my guess is that the maximum any philosophical naturalism can do is to recognize the most visible processes which are involved at the descriptive level. Beyond that we need phenomenological analysis to make progress (taken in a methodological sense). For instance, the descriptive level is the only one where naturalistic and phenomenological descriptions are compatible in a sense that naturalists refer to the same events Husserl consider part of the "life-world". Phenomenological descriptions deal with natural events in a direct manner but they provide open-meaning structures. The possibility to provide meaning implies that descriptive statements cannot stand alone for a scientific psychology (Husserl, 1970, p. 226). Phenomenological and naturalistic descriptions are both concerned with objective matters. But the difference between them arises from the fact that naturalists are satisfied with their criteria of objectivity which emerges from a combination between a strong belief in the objectivity of perceptual experiences and the direct relation of perceptual experience with language (what Hume and later Wittgenstein called "a pictorial language", meaning a language which describes reality the way it is). It is obvious they never considered that cognitive processes are reconstructive, not in a sense that reality would be an illusion but the interpretation of reality might be subjective. The problem with naturalistic descriptions is that they are built upon the assumption that language, mind, and matter follow the same rules, hence one cannot ultimately be wrong since to speak (think) is to mirror. That works if reducing ontological events to the same principle. Physicalism for instance as a branch of naturalism is ontoepistemologically speaking the most radical attempt to uniformize ontology.

The problem here is not to claim that conscious experiences are biologically grounded, as I already mentioned I am not concerned with biological functions of self-reflective experiences, rather with the fact that physicalism is not able to methodologically assess consciousness in its inner specificity. In short, it does not account for ontological specificity. Overall, strictly descriptive theories must prove that between the content they describe and the way they describe such content there is ontological identity. I guess I do not have to go into various metaphysical matters in order to prove that ontology is characterized by diversity and commonality, not by identity. Consider that each brain has a certain number of neurons, and the connections between these neurons differ from brain to brain. That is already a fundamental problem, not necessarily for science in general but certainly for a science which is guided by the assumption that if all things have ultimately the same cause they are necessarily explainable in the same terms. 
By the time the patient gets to the reflective stage he begins to understand the need to get out from thinking based only on perceptual rules (yet no contradiction with it) and so to move ahead ontoepistemological unitarism - the assumption according to which solving epistemological problems is solving ontological problems. To that extent a nonreductive theory of consciousness, at least from a methodological point of view, should account for both visible events and internal processes such as intentional experiences, or constructively assume they are at least co-occurring. If descriptive statements confer maximal authority to perceptual experiences (seeing is believing), this is to assume symmetry, and even unity between formal descriptions and the object they refer based on the ontological assumption according to which conscious experiences are entirely and accurately mirroring the external world, hence no need to assume something like inside/outside (internal/external) dimension of consciousness yet only one dimension: the outside. From a phenomenological point of view perceptual experiences are always accompanied by the meaning something perceived has for an observer in a sense that one cannot actually have a perceptual experience without conferring sense to what is perceived. But that is not to say that one has a full understanding of what is perceived. From that point of view, a nonreductive theory of consciousness should recognize that when describing something one is actually reflecting upon it. Consequently having a conscious experience is not simply outputting a certain state of mind but subjectively expressing what has been experienced.

Naturalism explains this matter following an old principle according to which all can be known directly (perceptually), but from a phenomenological point of view to know something means to consciously experience it, hence to intentionally confer meaning to what is perceived. In other words, to have the possibility to interact with the content of perceptual experiences. Naturalism informs us that consciousness is a response to external stimuli but this, again, does not explain why in the moment a subject makes a choice among a variety of stimuli there is always at least something subjective involved where that does not yet mean there would be something phenomenologically intentional but at least something subjective. In the moment I move from the understanding of a certain event to another I make a choice which means that I can provide a meaning to that certain event which is part of a broader set of similar events I can discern in part and in whole. I do not have to exclude the other events but I select one of them and that makes me responsible of my choice since it is my making that particular selection. The choice leads to an action for which I can be held accountable. If I consider only the visible actional dimension of the choice I will surely not be able to figure its intentional dimension, hence that humans "display" their internal understanding of the world to the level of a concrete intention. To put this back in the context, for the patient to begin the curing process he must think about the lost hand not to simply describe a hand. 
A strictly descriptive approach can at most inform about $a$ hand without providing the relation between a hand and the realization of the fact that it is his own hand he lost.

Finally, in order to be able to reconstruct the image of the lost hand (the reconstructive stage) in order to understand that the hand is actually gone, the patient must actualize the memory of the lost hand but he also must be capable of reconfering meaning to something which is not there anymore. In short, to think in absentia. For a neuroscientist, the problem is to find the part in the brain which is responsible of such experiences. For a philosopher, the job is to understand the conceptual implications for a general theory of consciousness. In any case for Husserl the reconstruction of past experiences is not only intentional but also specific which is the reason he would not hesitate to argue that no analysis is capable of fully describing it - in that sense a conscious experience is "transcendental", namely beyond what a theory might assume it is, yet not beyond the realm of nature. However, one shall not confound the intentional conferring of meaning with the power to structure the world according to one's will (something like a formal matrix that structures the natural world). Some of the critics of intentionality have expressed this peculiar concern regarding the phenomenological intentionality. When the patient reactualizes the lost hand he certainly does not produce a second hand which would begin to grow and replace the lost one but he reconstructs a model in his mind based on memory, sensation, etc. Between the lost hand and the mental model there isn't ontological symmetry although there is a real effect - the pain stops. In order for the pain to stop the patient must consciously recreate the meaning of the lost hand: "I do not have that hand anymore so my brain must stop sending out signals." In the mind of the patient a model of the absent hand is built and made intelligible for the brain.

The phantom limb could be a good illustration of what Husserl meant by intentionally (consciously) conferring meaning. A theory of consciousness which accounts for the correlation between mental models and ontological events is probably the best option we have although highly controversial. If one can intentionally (consciously) reset his beliefs regarding a certain event, that means the phenomenological theory of consciousness is accurate, which is not to say it solves the problem of consciousness in whole. It is at least clear that one can intentionally produce fictional objects as well as it is also clear that some beliefs can reshape to a certain extent ontology. However, the question here is what precisely (biologically) enables a subject to perform higher order correlations. Philosophical naturalism cannot solve this problem because it refuses to acknowledge the intentional character of experience. For Husserl that is certainly the reason, on the one hand, to bracket the consciousness, and, on the other hand, to argue for the need of a phenomenological psychology which can deal properly with conscious experiences. 


\section{Conclusion}

Although there are similarities, compatibility between phenomenology and naturalism is after all less relevant in the current circumstances than bridging phenomenology and natural sciences. (We can though hope to find compatibility if one recognizes with naturalistic psychology that consciousness is designed to deal with general biofunctions of consciousness while specific conscious experiences must be analyzed from a phenomenological point of view. Put it differently, there can be compatibility between the two theories, provided that what should drive psychology is the reality of conscious experiences.) But then again few phenomenologists have engaged that path certainly because the way they address the relation between phenomenology and natural sciences is still based on the idea according to which there is something "transcendental" which must be "embodied" instead to recognize there is something already in the world which needs a proper theory. It is true, again, that Husserl opposed the idea that psychology should be entirely governed by perceptual principles but I do not think that precludes the dialogue with natural sciences. Both the opponents and the defenders have actually twisted the interpretation of what Husserl considered to be a must-follow epistemological condition when engaging into a realistic analysis of consciousness. Instead of taking it as the pointing out of the need to avoid reductionism, they considered it as a fundamental obstacle in the elaboration of a phenomenological psychology. However, the philosophical attitude with respect to a phenomenological psychology should change. More precisely, those who are inclined to consider that phenomenology is destined to argue against natural sciences should probably revise this belief for the sake of a future phenomenology. There is no moral concern in here. Certainly, if one understands phenomenology only as a critique of naturalism and natural sciences at the same time, compatibility with natural sciences is excluded. But then he will have to explain why phenomenology is eventually a fundamental revision of the traditional theories of consciousness.

If conscious experiences are real (intentional) they are entitled to maximal philosophical and scientific relevance, namely to a psychology capable to address the psychophysical dimension of experience which means that moral concerns come always after and only based upon a nonreductive understanding of consciousness. Thus, when searching for compatibility between phenomenology and psychology one must keep in mind the epistemological primacy of consciousness (that is eventually the only axiom to follow) versus attempts to prescribe them. To that extent Husserl's critique of philosophical naturalism is in fact a critique of the prescriptiveness within philosophical naturalism (especially within logical positivism). This is to say that naturalism and in general any theory (including phenomenology) are not called to decree the nature and the character of conscious experiences, rather it is the reality of consciousness that prescribes formal attempts. In short, when applying formal models to ontological 
realities one needs to acknowledge their normative status which does not imply one has to dismiss their relevance. Philosophical naturalists and continentals seem to have overlooked this very important nuance within Husserl's criticism. From a strictly ethical point of view, it means to dismiss both implicit and explicit prescriptive moral theories since that involves ontological claims, and to draw a moral theory based upon the ontological status of consciousness in a sense that ethics is not possible without ontology. I am not suggesting here anything like Sartre's ethics of "authenticity" which does not emerge from the acknowledging of the intrinsic character of conscious experiences but from the tension between whatever Sartre thought conscious individuals are or how they become conscious, and whatever Sartre understands by an "oppressive system". Sartre's interpretation of classical phenomenology is ultimately unrelated with Husserl's theory of consciousness in a sense that for Sartre, and in general for any philosopher who follows the same logic, consciousness emerges from the interaction of a subject with social systems in this particular case - in here a subject becomes conscious by external interaction. That, however, is not a phenomenological idea.

To become conscious means, in my opinion, to already have a natural ability to consciously experience something. Therefore consciousness is natural in a sense that conscious experiences do occur in the world but it is their intrinsic specificity that goes beyond the theories we struggle to formulate with respect to consciousness. To that extent a classical phenomenology is that theory which has recognized the intrinsic natural complexity of conscious experience, not a theory which makes conscious experiences untouchable from a psychological point of view.

\section{References}

Chalmers, J. David (1996). The Conscious Mind. In search for a fundamental theory of mind. Oxford: Oxford University Press.

Chalmers, J. David (2010). The Character of Consciousness. Oxford: Oxford University Press.

Churchland, P. M. (1988). Matter and Consciousness: A Contemporary Introduction to the Philosophy of Mind. Cambridge, MA: MIT Press.

Delescu, L. (2009). La possibilité du naturalisme phénoménologique. Paris: L'Harmattan.

Dummett, Michael A. E. (2010). Nature and the Future of Philosophy. New York: Columbia University Press.

Flanagan, O. (2001). Dreaming Souls: Sleep, Dreams and the Evolution of the Conscious Mind. New York: Oxford University Press.

Hirstein, W, \& Ramachandran, V.S. (1997). Capgras syndrome: a novel probe for understanding the neural representation and familiarity of persons. Proceedings of the Royal Society of London, 264, 437444.

Hume, D. (1739/1978). A Treatise of Human Nature (ed. by L. A. SelbbyBigge). Oxford: Clarendon Press. 
Husserl, E. (1931/1960). Cartesian Meditations (trans. Dorion Cairns). Dordrecht: Kluwer.

Husserl, E. (2008). Logical Investigations: Volume I (trans. J. N. Findaly). London and New York: Routledge.

Husserl, E. (1925/1977). Phenomenological Psychology: Lectures, Summer Semester 1925 (trans. John Scanlon). Den Haag: Martinus Nijhoff.

Husserl, E. (1970). The Crisis of European Sciences and Transcendental Phenomenology. Chicago: Northwestern University Press.

Merleau Ponty, M. (1945/1976). Phénoménologie de la perception. Paris: Gallimard.

Nagel, T. (1965). Physicalism. The Philosophical Review, Vol. 74, No. 3, 339356.

Petitot, J., Varela, F., Pachoud, B., \& Roy, J.M. (1997). Naturalizing the Phenomenology. Issues in Contemporary Phenomenology and Cognitive Sciences. Stanford: Stanford University Press.

Putnam, Hillary (2002). The Collapse of the Fact/Value Dichotomy and Other Essays. Cambridge, MA: Harvard University Press.

Ramachandran, V. S. \& Hirstein, W. (1998). The perception of phantom limbs: The D. O. Hebb lecture. Brain, 121, 16031630.

Searle, R J. (2010). Making the social world: The Structure of Human Civilization. New York: 